Egyptian Journal of Aquatic Biology \& Fisheries

Zoology Department, Faculty of Science,

Ain Shams University, Cairo, Egypt.

ISSN $1110-6131$

Vol. 23(4): 421 - 436 (2019)

www.ejabf.journals.ekb.eg

\title{
Utilization of Nannochloropsis oceanica alga for biodiesel production and the de-lipidated biomass for improving Red tilapia aquaculture
}

\author{
Ali M. Abugrara ${ }^{1}$, Heba S. El-Sayed ${ }^{2 *}$, Mohamed A. A. Zaki ${ }^{3}$ and \\ Abd El-Aziz M. Nour ${ }^{4}$
}

1- Lecturer, Marine resources department, Faculty of Natural Resources and environmental sciences, Omar Al-Mokhtar University, El-Beda, Libya.

2- Associate professour in aquaculture division, National Institute of oceanography and fisheries, Qait Bay, Alexandria, Egypt.

3- Head of Animal and Fish production department, Professour of fish husbandary faculty of Agriculture (El-Shatby), Alexandria University, egypt.

4- Professour of Animal and fish Nutrition, department of Animal and Fish production, faculty of Agriculture (El-Shatby), Alexandria University, egypt. *Corresponding Author: hebasaad2222@yahoo.com

ARTICLE INFO
Article History:
Received: July 19, 2019
Accepted:Sept. 26, 2019
Online: Oct. 2019

Keywords:

Nannochloropsis

Biodiesel

Red tilapia

Aquaculture

Organic sources

Growth performance

Biochemical analysis

\section{INTRODUCTION \\ INTRODUCTION}

This work was carried out, firstly for investigating the different effects of various organic carbon sources [fructose (A), lactose (B), glucose (C)], and nitrogen sources [poultry manure extract (PM) and rumen liquor (RL)] which used at ratio 50:50\% $\mathrm{F} / 2$ medium on maximizing production of biodiesel from the marine microalga Nannochloropsis oceanica. Secondly, we apply the residual lipid-free biomass as feed additives in Red tilapia aquaculture. In phase1, the biomass (DW), biodiesel contents and biochemical compositions of $N$. oceanica were determined. The results showed varied biomass and biochemical analysis in DW bases between treatments. However, A was achieved significantly the maximum DW for the algal biomass and protein percentage, whereas lipid accumulation was the most in RL as well as achieving the highest biodiesel content. In phase 2, algal biomass by-product (lipid-free) from the superior treatments A and RL were applied at 4 rates $(1,2,3$ and 4$)$ for concentrations $25,50,75 \& 100 \%$, respectively that substituting soybean for feeding red tilapia larvae as compared with control $\mathrm{CO}$. The initial weight and length of the larvae were $0.32 \mathrm{~g}$ and $1.9 \mathrm{~cm}$, respectively continued for a duration of 30 days of the experiment. After the end of the experimental period, growth performance, survival percentage (SR\%) and biochemical analysis were estimated. The results revealed that SR\% was higher significantly for RL2 than A1 $(93 \%$ \& 90\%) as compared to control (86.7\%). Accordingly, red tilapia carcass attained maximum protein contents for diets A1 \& RL2 in whereas lipid content was maximum in control. Finally, authors suggesting the use of Roman liquor as a novel treatment for cost-effective promoting biodiesel content and the remained biomass with 50\% substitution of soybean in the diet (RL2)achieved also good results for improving red tilapia aquaculture.

Microalgae was considered as one of the main live foods for rotifers, Cladoceran and other zooplankton besides larvae of fish and shrimp (Gallardo et al., 1995). From the nutritional point of view, it is well affirmed that many freshwater and 
marine microalgae play bivotal role in providing energy, essential nutrients such as proteins, lipids, carotenes, vitamins, amino acids, polyunsaturated fatty acids and essential minerals for proper development of aquatic organisms (Vymazal, 1995; Yamaguchi, 1997; Habib et al., 2003). Organic media were mostly used in early experimental works to grow algae (Shelf et al., 1978). Optimizing the appropriate culture media for mass culture microalgae biomass is very important in the industrial scale production. Culture media for microalgae should easy to prepare $\mathbf{F} / \mathbf{2}$ medium that commonly used for small-scale indoor culture, was expensive and difficult to set up for outdoor mass culture, acts as the main hurdle for biofuel production. Thus, agricultural fertilizers are commercially used as a replacement for F/2 culture medium (Sanchez-Saavedra et al., 2005). They studied the growth of microalgae, while others investigated the biochemical constituents of the microalgae as response to the medium (Feng et al., 2011; Martinez Cordova et al., 2012). Nitrogen concentration and also nitrogen source play a critical role in enhancing the lipid and biomass productivity for biodiesel production (Vega et al., 2010). Bondioli et al. (2012) reported that Nannochloropsis has a high lipid (maximum 68.5\%) and lipid productivity (maximum $271 \mathrm{ml} / \mathrm{l} /$ day), which make it a good source for biofuel production. Additionally, biodiesel from microalgae has been demonstrated to have broad application prospects, but these currently still remain at the exploratory stage (Junying et al., 2013). Nevertheless, a major hitch for microalgae oil production is its relatively high costs, which is supposed to be overcome by the technology developments (Rois et al., 2013). The main environmental factors affecting carbohydrate accumulation are light intensity, $\mathrm{pH}$, salinity and temperature, while the nutritional factors include the abundance and source of nitrogen, carbon, phosphorus, sulfur and iron (Chen et al., 2013; Markou et al., 2014). Nutrient consumption from different manure-based ADE products and industrial wastes have been evaluated for production of biomass, lipids, carbohydrates and proteins in Chlorella species, and effluent sources have poultry litter (Singh et al., 2011).

The mixotrophic cultivation, using either organic or inorganic $\mathrm{CO}_{2}$ carbon sources in presence of light, is a good strategy to obtain large biomass and higher lipid content (Choi and Yu, 2015; Lin and Wu, 2015). Sharma et al. (2016) studied the effect of different carbon sources (Fructose, Glycerol, Glucose and Sodium acetate) with determining growth and lipid content on five Chlorella species cultivated in BG11 medium at the same condition.

Rumen liquor is one of the most sophisticated microbial ecosystems in nature consists of all the microorganisms that live in a certain area. Biotic and abiotic factors functioning together, that provides the bioreactor (the rumen) and the pretreated carbon source (plant material), and receives in turn carbon and energy in a suitable chemical form. Overall the system can be viewed as one "super metabolism". Thus, the rumen perfectly a similar solution to a current industrial problem called the bio refinery that aims to the bioconversion of lignocellulosic material into fuels and chemicals (Sauer et al., 2012). Rumen contains tannins (Jayanegara et al., 2009) and saponins (Pen et al., 2006). At low concentrations, tannins may save beneficial effects by regulating the rate of nitrogen release in the rumen (Naumann et al., 2017) but a slight change in the rate of disintgration of feeds by tannins could decrease the rate of release of different nutrients mainly proteins, which in turn, could lead to an increase of microbial efficiency (Makkar, 2005). Also, tannins and saponins are capable of modifying the chemical synthesis of the microbe, inducing changes in the whole microbial fraction, methane production and microbial protein structure (Bhatta et al., 2009). 
Jain and Singh (2013) indicated the potentiality using of ruminants dung (cow ash) and Asmare et al. (2014) from dairy manure to provide the nutrients to the culture medium that lower its high cost and make it economic culture for algal cultivation. Han et al. (2016) proved that microalgae-bacteria cultures combination under mixotrophic conditions are also suitable effective strategy for microalgal cultivation. Ajitha Mol, (2016) recorded high production of Brachionus roundiformis by using different media containing Nannochloropsis alga supplemented cow dung, rice bran, yeast and poultry manure respectively comparing with standered medium.

Recently, aquaculture technologies were developed rapidly to meet human demand as supplementation with dietary lipids or proteins (Ashour et al., 2019). They investigated also application of lipid-free algal biomass in enhancing Artemia development and survival for improving aquaculture (El-Kassas et al., 2016). However, Heflin et al. (2012) concluded that protein content is the most important components in aquaculture feeds. In that respect, microalgae are considered the most important feed sources in aquaculture due to their nutritional value and their ability to synthesize and accumulate great amounts of $\omega 3$-polyunsaturated fatty acid (PUFA) (Patil et al., 2007). Also, microalgae are a rich source of protein which can be used as a cheaper food option for animals and fish that able to replace the existing expensive technologies (Hasan et al., 2009; Abomohra et al., 2014) as well as providing protective effect as a feed supplement against the heavy metals accumulation in fish muscles and disease resistance (Hasanein et al., 2018).

Nannochloropsis is a genus of unicellular microalgae that considered as one of the most valuable marine microalgae that can be used in aquaculture because of small cellular size and high nutritional value (Wan et al., 2013). Some of Nannochloropsis species are used in marine hatcheries as an important food for zooplanktonic rotifer Brachionus plicatilis and as a source of eicosapentaenoic acid (EPA), (Chen et al., 2015). However, studies on impact of delipidated biomass of that alga in aquaculture nutrition are very scarce.

The complete utilization of algal biomass may comprise the association of different technologies (Behera et al., 2015). Algal lipids can be plucking out for production of biofuel and the residual solids, which are mostly proteins and carbohydrates are appropriate for larvae feeding (Mondal et al., 2017).

Accordingly in this study the biomass yield, lipid, protein and carbohydrates production from marine microalga Nannochloropsis oceanica will be investigated for supplementing a standard inorganic medium $\mathrm{F} / 2$ at $50 \%$ concentration with different organic carbon sources (fructose, lactose, glucose) and nitrogen sources poultry manure and Rumen liquor) then assess best conditions to maximize the yield of biodiesel from the complete cell and moreover evaluate inclusion of residual delipidated biomass for improving Red tilapia aquaculture.

\section{MATERIALS AND METHODS}

\section{Algal species}

The marine microalga Nannochloropsis oceanica obtained from algal unit in the marine hatchery of the National Institute of Oceanography and Fisheries, Alexandria, Egypt. The algal strain was cultured in sea water enriched with F/2 medium (Guillard and Rhyter,1962) and the salinity of seawater was ( $35 \pm 1 \mathrm{ppt})$. 


\section{The Experimental design}

The experiment was carried out in this study in two phases: Phase 1 for evaluating different carbon sources [fructose (A), lactose (B), glucose (C)], and nitrogen sources [poultry manure extract $(\mathrm{PM})$ and rumen liquor (RL)] at ratio $50: 50 \%$ to $\mathrm{F} / 2$ medium for culturing the microalga $N$. oceanica as compared with control $(100 \% \mathrm{~F} / 2)$. The culture system was started in indoor at $(250 \mathrm{ml}-5 \mathrm{~L})$ and then upscaled in mass cultures outdoor at (45L plastic bags) in triplicates for determining the growth in terms of biomass and biochemical composition besides the biodiesel production at the end of exponential growth phase of these cultures. The different sources were prepared in the media at concentrations $0.5 \mathrm{~g} / \mathrm{L}$ and then added the rest $\mathrm{F} / 2$ medium at $50 \%$ concentration as shown in Table 1 . The duration of the cultures were 10 days then the algal biomass was harvested and estimated.

Table 1: Dietary carbon and nitrogen sources A,B,C,PM and RL levels .

\begin{tabular}{lccccc}
\hline Standard F/2 & $50 \%$ & $50 \%$ & $50 \%$ & $50 \%$ & $50 \%$ \\
\hline Fructose (A) & $50 \%$ & - & - & - & - \\
Lactose (B) & - & $50 \%$ & - & - & - \\
Glucose (C) & - & - & $50 \%$ & - & - \\
Poultry manure extract (PM) & - & - & - & $50 \%$ & - \\
Rumen liquor (RL) & - & - & - & - & $50 \%$ \\
\hline
\end{tabular}

\section{Determination of algal biomass:}

The biomass was chemically harvested (Fig 1. A) through flocculation method described by (Sales\&Abreu,2014) using $\mathrm{NaOH}(5 \%)$ for 10 minutes.Then the water was siphon out and the flocculants were filtered through plankton net with mesh20 micron.The wet biomass was then dried in oven at $50 \mathrm{C}^{\circ}$ and weighed in $\mathrm{g} / \mathrm{L}$ to determine algal growth in each medium and stored for further using in biodiesel extraction.

\section{Extraction and purification of total lipids:}

The total lipids were exhaustively extracted by the addition of $200 \mathrm{ml}$ of chloroform and methanol mixture $(2: 1 \mathrm{v} / \mathrm{v})$ to a known weight of dried algal biomass using Folch method (1957). Then the obtained total lipids were weighed as g/g dry biomass for further oil(biofuel) and biodiesel extractions.

\section{Biodiesel Extraction and purification methods (methylation)}

By using Radwan esterification method (1978), take the oil -hexane extracted from the total lipid and placed in the Falcon glass tubes with $2 \mathrm{ml}$ benzene and then add $1 \%$ methanolic sulfuric acid and close the bottles tightly, then was placed in the oven at $90^{\circ} \mathrm{C}$ for an hour and a half and after taking it out of the oven add distilled water and bilge well, then add petroleum ether 60/80 in stages until the biodiesel collects on the surface, we pull it out with a syrenge, put it in the beaker and leave it until the chemicals evaporate and the biodiesel remains.
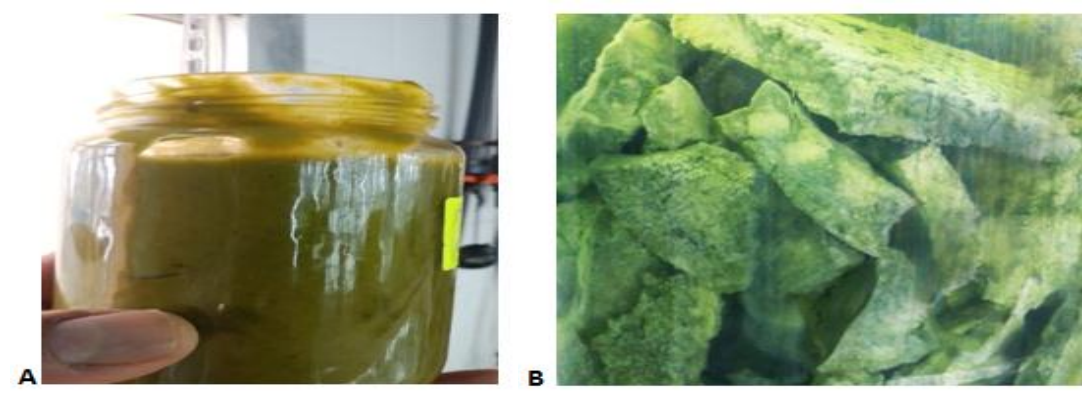

Fig. 1: Showing (A): Harvested Biomass, (B) The delipidated form of dried algal Biomass of N. Oceanica. 


\section{Phase 2:}

Concerning the formulation of the experimental fish diets by using the residual lipid-free algal biomass as substitusion for Soybean in the main microdiet components for feeding red tilapia post larvae.

After extracting the oil, the residual biomass was washed well with dechlorinated tap water to get rid of any chemicals that have been remained then dried as shown in Fig. 1 (B), then grinded and incorporated into the fish feed mixture as shown in Table (2) for the application experiment on Red tilapia larvae. The larval initial weight was $(0.32 \pm 0.1)$ whereas the average initial length was $(1.9 \mathrm{~cm} \pm 0.1)$.

The stocking denisty was 15 larvae per aquarium $20 \mathrm{~L}$ with experiment duration for 30 days. At the end of the experiment, the larval growth parameters and the biochemical compositions of the fish body were determined.

Table 2: Composition (\%) of the experimental diets containing different inclusion levels of lipid-free algal biomass as substitusion for Soybean

\begin{tabular}{lccccc}
\hline \multicolumn{1}{c}{ Ingredient \% } & \multicolumn{5}{c}{ Experimental diets } \\
\cline { 2 - 6 } & Control & $\mathbf{2 5 \% ( 1 )}$ & $\mathbf{5 0 \%}(\mathbf{2})$ & $\mathbf{7 5 \%}(\mathbf{3})$ & $\mathbf{1 0 0 \% ( 4 )}$ \\
\hline Fish meal & 23 & 23 & 23 & 23 & 23 \\
Soybean meal & 23 & 17.25 & 11.5 & 5.5 & ---- \\
Algae meal ( A or RL) & ------- & 5.75 & 1.51 & 17.5 & 23 \\
Corn gluten meal & 2 & 2 & 2 & 2 & 2 \\
Wheat bran & 7 & 7 & 7 & 7 & 7 \\
Yellow corn & 40 & 40 & 40 & 40 & 40 \\
Corn oil & 3 & 3 & 3 & 3 & 3 \\
Vitamin. Mix & 2 & 2 & 2 & 2 & 2 \\
Total & 100 & 100 & 100 & 100 & 100 \\
\hline
\end{tabular}

\section{Biochemical analyses}

Proteins and carbohydrates contents of the alga N.oceanica as well as red tilapia body carcass were determined according to Egan et al. (1981) and Dubois et al. (1956), respectively. Whereas, ash and fiber were analysed according to AOAC (2000).

\section{Biological parameters}

\section{The following parameters were calculated:}

WG (weight gain) = Wt-W0 (mg/fish) $($ Bordy, 1945)

ADG (average daily gain) $=\mathrm{Wt}-\mathrm{W} 0 / \mathrm{n}(\mathrm{mg} /$ fish/day $)($ Bordy, 1945$)$

SGR $($ specific growth rate $)=100 \times(\operatorname{lnWt}$-lnW0)/days $($ Castell and Tiews, 1980$)$

SR $($ survival rate $)=($ No. of fish at end / No, of fish at the start $) \times 100$ (Ricker, 1975 , Newman and 1983)

TLG $(\mathrm{cm} /$ fish $)$ total length gain $=\{$ Average final length $(\mathrm{cm})-$ Average initial length (cm)\}

Condition factor: $($ Kvalue $)=($ body weight. $\mathrm{g}) /\left(\right.$ body length, $\left.\mathrm{cm}^{3}\right) \times 100$ (Fisher, et al., 1996)

Feed intake (FI) in (g). This is the amount of feed given or supplied during the experimental period

FCR (food convertion ratio) = dry matter intake $(\mathrm{g}) /$ body weight gain $(\mathrm{g})$

PER $($ Protein efficiency ratio $)=$ weight gain $(\mathrm{g}) /$ protein intake $(\mathrm{g})$

Energy gain $(\mathrm{MJ})=\mathrm{Et}-\mathrm{E} 0$

Energy retention $(\mathrm{ER}, \%)=($ Et-E0)/Energy intake $(\mathrm{MJ}) \times 100$

All above formulae were used and described by (El-Dahhar et al., 2016). 


\section{Statistical analysis}

Descriptive statistics of the studied trails were calculated using Summary procedure of SAS (2004). The effect five factors of chemical composition of microalgae, two factors add microalgae of diets on larvae Red tilapia.

\section{RESULTS}

\section{The algal growth}

As shown in Figure (2), the algal growth represented in biomass reached its best records by A followed by RL, PM \& C while the lowest biomass was obtained by $\mathrm{B}$ and control.

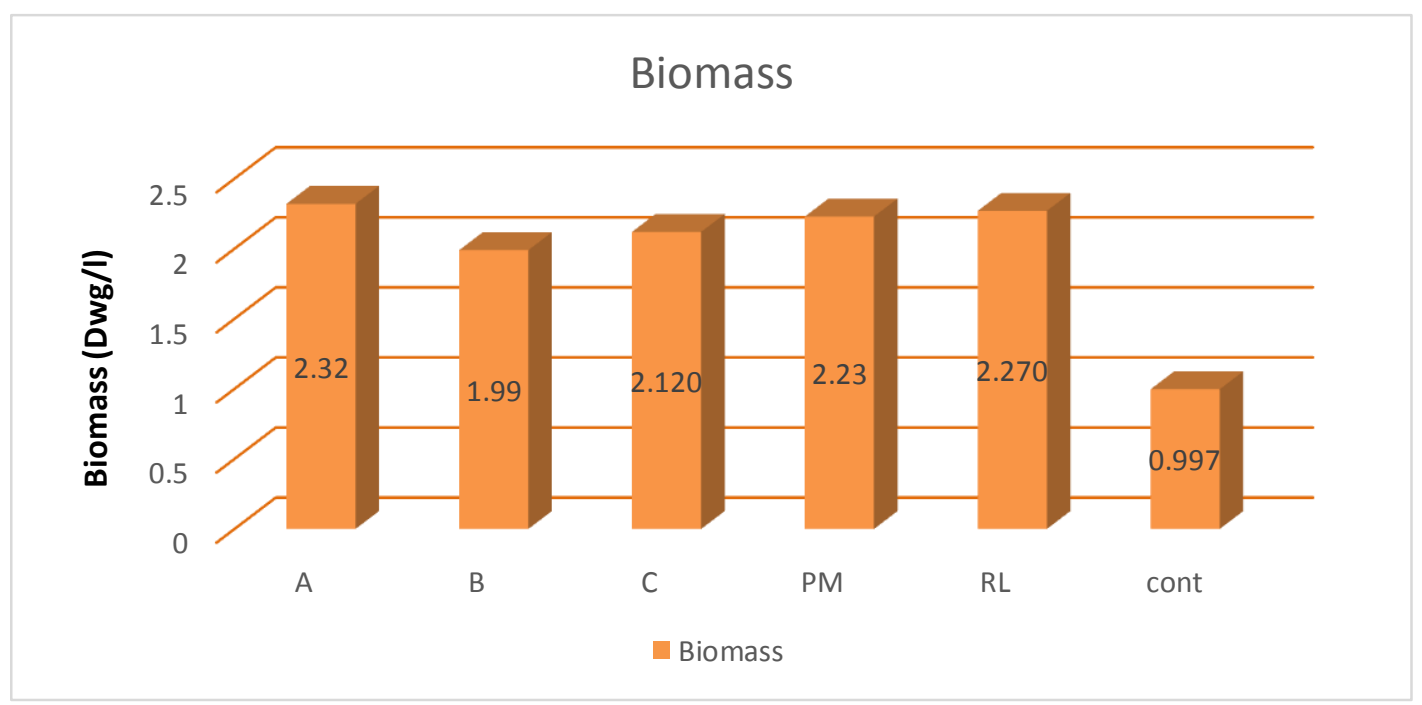

Fig. 2: The effect of the different organic media sources on N.oceanica biomass(Dw g/L)

\section{Biochemical composition of $N$. oceanica}

In Figure (3) the results concerning the impact of different sources of carbon, (fructose (A), lactose (B), glucose (C) )and the selected nitrogen sources, (poultry manure (PM) and rumen liquor (RL)) on the biochemical analysis of the alga N.oceanica showed highly significant differences $(\mathrm{P}<0.05)$ between all treatments. The highest protein shown by A followed by control(cont) \&C while the lowest was shown by PM. The highest lipid was demonstrated by RL followed byPM while the lowest value was obtained by control \&A. On the other side maximum carbohydrates data was established by C,A, B and control respectively while the lowest was shown by PM and RL. 


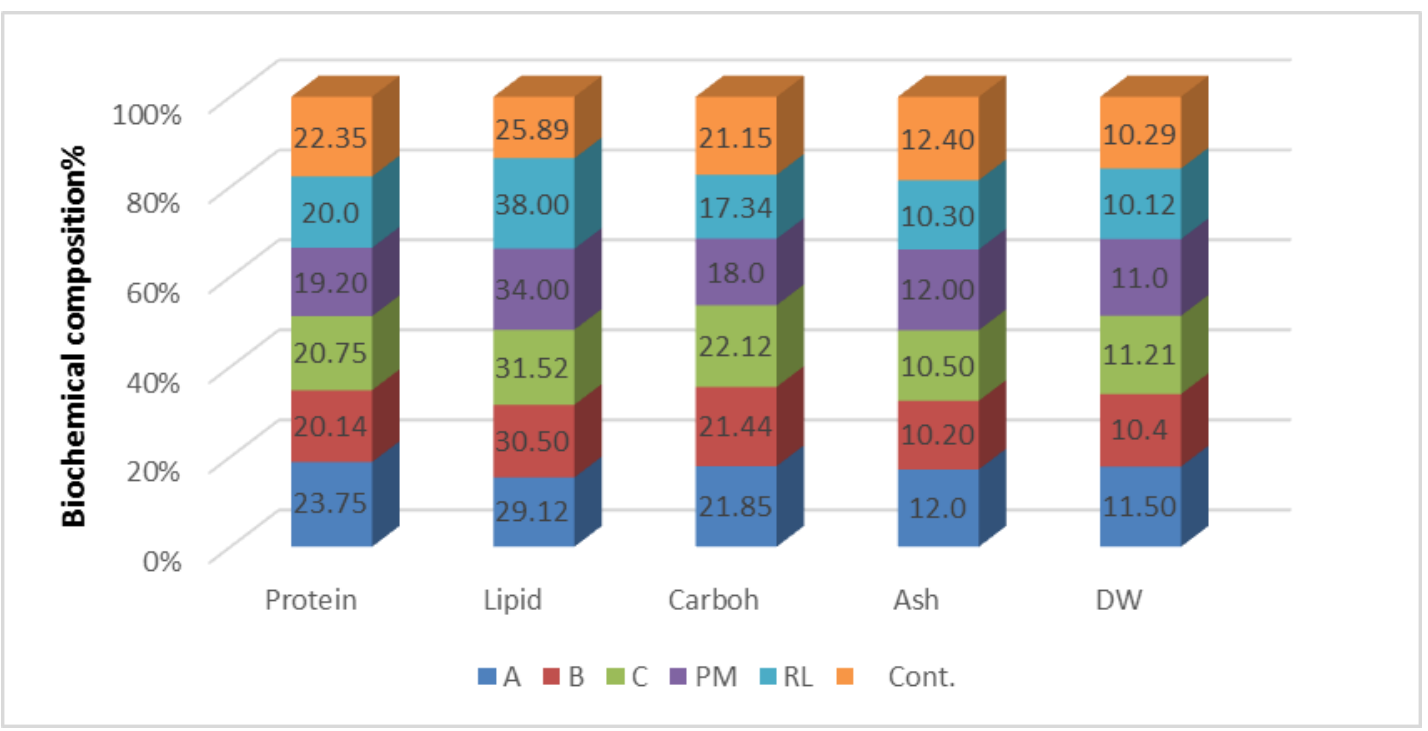

Fig. 3: The effect of the different organic media sources on the biochemical composition of N.oceanica

\section{Biofuel (oils) content:}

Figure (4) showed the biofuel (oil) percent in the total lipid of the biomass (Dw) of the alga $N$. oceanica cultured in the different organic media sources. The results indicated that the oil \% increased from A to RL in an ascending order compared with control contained the lowest percent.

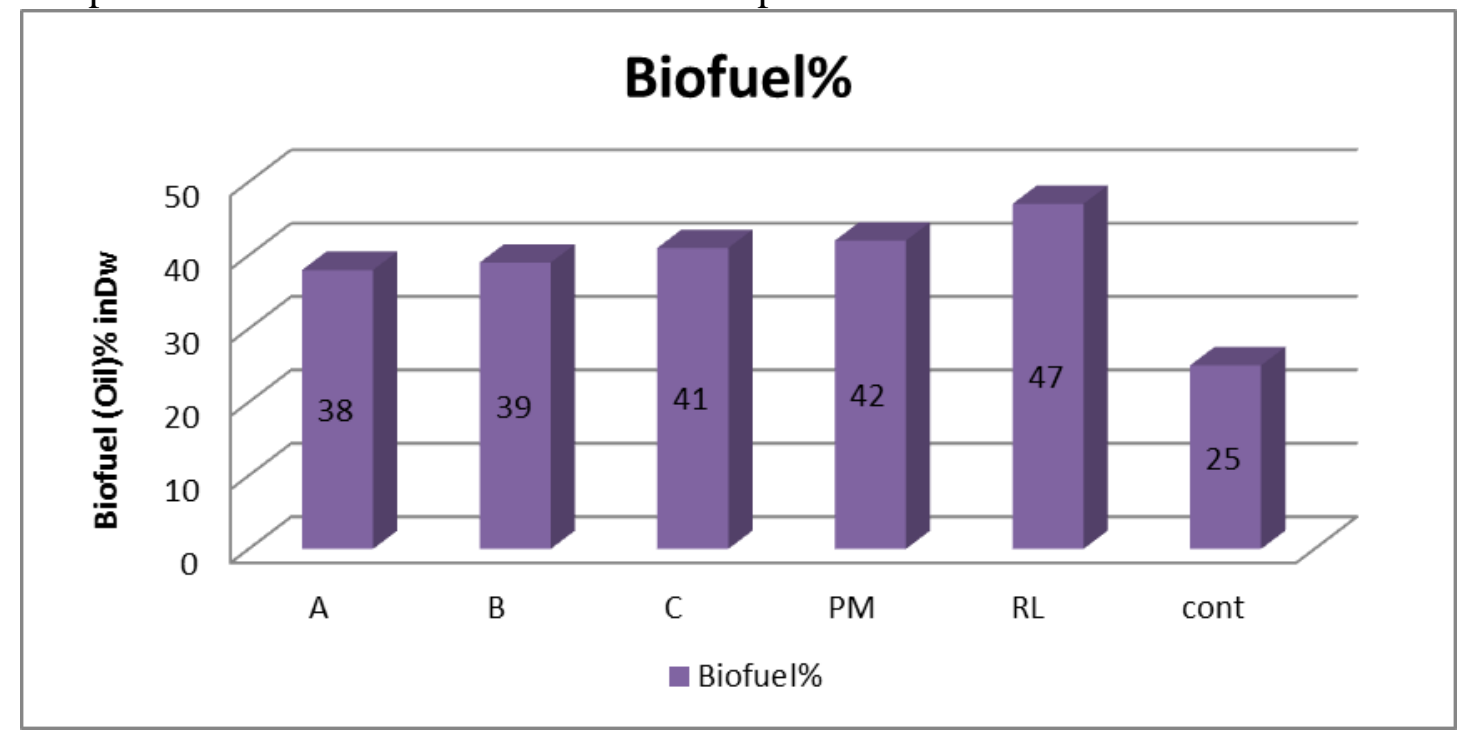

Fig. 4: Oil hexane extract percentages(oil\% in total lipid Dw) from the alga N.oceanica biomass in the different organic media sources.

Biodiesel contents in Biofuel(oil) of $N$. oceanica:

Similarly,In Figure (5). The results demonstrated that the highest biodiesel percentages were obtained by RL,PM and C respectively, while the lowest percent was showed by control \& A. 




Fig. 5: Methylated oil ( Biodiesel) percentage in the oil produced from the alga N.oceanica in the different organic media sources.

\section{Fatty acid profiles in the produced biodiesel in the different organic media}

In Table (3), concerning the biodiesel analysis, the highest total saturated fatty acids (TSFA) percentage was obtained by RL, PM, B, C and A, respectively as compared with control. This increase in saturated fatty acid (SFA) was due to increasing palmitic acid (C16:0) in the same last order against control.

On the other hand, the highest unsaturated fatty acid contents (UFA) were achieved by control, A, C, B and PM in descending order. However, the highest polyunsaturated fatty acids (PUFA) especially $\omega 3$ FAs were obtained by A as compared with other treatments and control .Otherwise, the maximum total fatty acids (TFAs)contents were achieved by RL followed byPM,C,B \&A while control had the lowest value.

Table 3 : Fatty acid profile of the produced biodiesel ( as \% of the total fatty acids)

\begin{tabular}{lcccccc}
\hline Treatment Fatty acids & A & B & C & PM & RL & Cont \\
\hline Saturated fatty acid & & & & & & \\
C6:0 & 0.4 & 0.2 & 0.0 & 0.1 & 0.0 & 0.0 \\
C 8:0 & 0.1 & 0.0 & 0.1 & 0.3 & 0.0 & 0.1 \\
C10:0 & 0.0 & 0.0 & 0.1 & 0.1 & 0.0 & 1.6 \\
C11:0 & 0.2 & 0.0 & 0.0 & 0.0 & 0.0 & 0.3 \\
C12:0 & 0.7 & 0.6 & 0.4 & 0.7 & 0.3 & 0.5 \\
C13:0 & 0.0 & 0.0 & 0.1 & 0.1 & 0.2 & 0.7 \\
C14:0 & 11.1 & 10.6 & 9.4 & 10.5 & 12.3 & 11.3 \\
C15:0 & 1.4 & 1.5 & 1.7 & 1.9 & 1.6 & 6.3 \\
C16:0 & 58.7 & 61.5 & 61.0 & 64.3 & 70.0 & 33.7 \\
C17:0 & 0.5 & 0.4 & 0.6 & 0.6 & 0.7 & 0.4 \\
C18:0 & 2.3 & 2.1 & 2.0 & 2.2 & 2.6 & 10.4 \\
C20:0 & 2.2 & 2.9 & 2.3 & 2.1 & 1.0 & 0.0 \\
Monounsaturated FA & & & & & & \\
C14:1 & 0.5 & 0.4 & 0.4 & 0.7 & 0.3 & 10.5 \\
C15:1 & 0.3 & 0.9 & 0.5 & 0.3 & 0.6 & 7.7 \\
C16:1 & 8.9 & 4.9 & 9.3 & 2.1 & 1.5 & 7.6 \\
C17:1 & 0.0 & 0.0 & 0.1 & 0.3 & 0.1 & 0.6 \\
C18:1 09 & 3.5 & 4.5 & 3.2 & 2.0 & 0.6 & 4.1
\end{tabular}




\begin{tabular}{|c|c|c|c|c|c|c|}
\hline C20:1 & 0.8 & 0.4 & 0.5 & 0.3 & 0.5 & 0.0 \\
\hline \multicolumn{7}{|c|}{ Polyunsaturated FA } \\
\hline 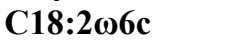 & 3.8 & 4.1 & 3.5 & 2.0 & 3.4 & 0.6 \\
\hline 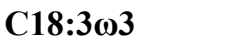 & 1.7 & 1.1 & 0.5 & 0.3 & 0.3 & 0.0 \\
\hline  & 2.9 & 4.0 & 4.2 & 9.1 & 4.0 & 2.8 \\
\hline SFA & 77.6 & 79.7 & 77.8 & 82.9 & 88.7 & 65.3 \\
\hline UFA & 22.4 & 20.3 & 22.2 & 17.1 & 11.3 & 34.7 \\
\hline MUFA & 14.0 & 11.1 & 14.0 & 5.7 & 3.6 & 30.5 \\
\hline PUFA & 8.4 & 9.2 & 8.2 & 11.4 & 7.7 & 4.2 \\
\hline PUFAs- $\omega 3$ & 1.7 & 1.1 & 0.5 & 0.3 & 0.3 & 0.8 \\
\hline PUFAs- $\omega 6$ & 6.7 & 8.1 & 7.7 & 11.1 & 0.4 & 3.4 \\
\hline TFAs (mg.L L $\left.^{-1}\right)$ & 298.9 & 316 & 366.6 & 379.9 & 442 & 215 \\
\hline
\end{tabular}

\section{Chemical composition of diets}

Table 4 showed the effect of different diets $(25,50,75$ and 100\%) in the chosen treatments of the delipidated microalgal biomass as substitution alternatives for soybean in the formulated diets on feeding red tilapia larvae. The growth parameters and survival compared to control (CO) were monitored. The results indicated that most of diets analysis in lipid, ash, fiber and carbohydrates were significantly higher in control. Total protein contents were higher in A1>RL2 $>\mathrm{CO}$ while the lowest was contained by A4 and RL4 with significance $(\mathrm{P}<05)$.

Table 4: The effect of the different levels of lipid-free algal biomass on chemical composition variability of the diets of red tilapia

\begin{tabular}{ccccccc}
\hline Treatments & Protein & lipid & Ash & Fiber & Carbohydrates & Gross energy \\
\hline CO & 29.79 & 6.59 & 5.89 & 3.59 & 55.14 & 448.32 \\
A1 & 29.88 & 6.48 & 6.41 & 2.82 & 54.55 & 454.02 \\
A2 & 29.76 & 6.35 & 6.93 & 2.68 & 54.36 & 451.66 \\
A3 & 29.68 & 6.25 & 7.48 & 2.54 & 53.98 & 449.55 \\
A4 & 29.57 & 6.12 & 7.95 & 3.01 & 53.35 & 444.70 \\
RL1 & 29.71 & 6.49 & 6.26 & 2.58 & 54.91 & 455.70 \\
RL2 & 29.77 & 6.38 & 6.62 & 2.3 & 54.99 & 454.71 \\
RL3 & 29.64 & 6.26 & 7.01 & 3.02 & 53.94 & 449.59 \\
RL4 & 29.55 & 6.16 & 7.35 & 2.82 & 54.02 & 448.24 \\
\hline
\end{tabular}

\section{Biological parameters}

Table 5 showed the feed intake, survival\% and growth performance parameters measurements. The results revealed that the most of the analysis values were promoted significantly in RL2 and A1 compared with other treatments and control at significance $(\mathrm{P}<0.05)$.

Table 5: The effect of diets composition on growth measurments of Red tilapia post larvae.

\begin{tabular}{lccccccccc} 
Treatment & $\begin{array}{c}\text { FI } \\
(\mathbf{g})\end{array}$ & $\begin{array}{c}\text { SR } \\
\%\end{array}$ & $\begin{array}{c}\text { WG } \\
\text { g/fish }\end{array}$ & $\begin{array}{c}\text { ADG } \\
\text { g/fish/day }\end{array}$ & $\begin{array}{c}\text { TLG } \\
\text { Cm/fish }\end{array}$ & $\begin{array}{c}\text { FCR } \\
\text { g }\end{array}$ & $\begin{array}{c}\text { K } \\
\text { value }\end{array}$ & $\begin{array}{c}\text { PER } \\
\text { g }\end{array}$ & $\begin{array}{c}\text { SGR } \\
\text { \%/day }\end{array}$ \\
\hline CO & $20.53 \pm$ & $86.67 \pm$ & $0.56 \pm$ & $0.88 \pm$ & $0.10 \pm$ & $1.44 \pm$ & $0.92 \pm$ & $0.09 \pm$ & $3.34 \pm$ \\
& $0.90^{\mathrm{e}}$ & $8.85^{\mathrm{d}}$ & $0.15^{\mathrm{e}}$ & $0.12^{\mathrm{e}}$ & $0.01^{\mathrm{h}}$ & $0.52^{\mathrm{e}}$ & $0.42^{\mathrm{e}}$ & $0.06^{\mathrm{f}}$ & $0.94^{\mathrm{h}}$ \\
A1 & $23.20 \pm$ & $90.00 \pm$ & $0.69 \pm$ & $0.93 \pm$ & $0.26 \pm$ & $1.50 \pm$ & $1.05 \pm$ & $0.15 \pm$ & $4.25 \pm$ \\
& $0.90^{\mathrm{a}}$ & $8.85^{\mathrm{b}}$ & $0.15^{\mathrm{d}}$ & $0.12^{\mathrm{b}}$ & $0.01^{\mathrm{c}}$ & $0.52^{\mathrm{c}}$ & $0.42^{\mathrm{d}}$ & $0.06^{\mathrm{a}}$ & $0.94^{\mathrm{b}}$ \\
$\mathbf{A 2}$ & $21.30 \pm$ & $86.67 \pm$ & $0.64 \pm$ & $0.92 \pm$ & $0.25 \pm$ & $1.13 \pm$ & $0.89 \pm$ & $0.13 \pm$ & $4.12 \pm$ \\
& $0.90^{\mathrm{b}}$ & $8.85^{\mathrm{dd}}$ & $0.15^{\mathrm{c}}$ & $0.12^{\mathrm{c}}$ & $0.01^{\mathrm{e}}$ & $0.52^{\mathrm{g}}$ & $0.42^{\mathrm{f}}$ & $0.06^{\mathrm{b}}$ & $0.94^{\mathrm{c}}$ \\
$\mathbf{A 3}$ & $20.83 \pm$ & $70.78 \pm$ & $0.66 \pm$ & $0.90 \pm$ & $0.20 \pm$ & $1.12 \pm$ & $0.82 \pm$ & $0.12 \pm$ & $3.89 \pm$ \\
& $0.90^{\mathrm{c}}$ & $8.85^{\mathrm{e}}$ & $0.15^{\mathrm{b}}$ & $0.12^{\mathrm{d}}$ & $0.01^{\mathrm{c}}$ & $0.52^{\mathrm{f}}$ & $0.42^{\mathrm{h}}$ & $0.06^{\mathrm{c}}$ & $0.94^{\mathrm{e}}$ \\
$\mathbf{A 4}$ & $20.77 \pm$ & $70.00 \pm$ & $0.56 \pm$ & $0.80 \pm$ & $0.13 \pm$ & $0.89 \pm$ & $0.54 \pm$ & $0.11 \pm$ & $3.74 \pm$ \\
& $0.90^{\mathrm{d}}$ & $8.85^{\mathrm{f}}$ & $0.15^{\mathrm{ee}}$ & $0.12^{\mathrm{f}}$ & $0.01^{\mathrm{f}}$ & $0.52^{\mathrm{ee}}$ & $0.42^{\mathrm{i}}$ & $0.06^{\mathrm{d}}$ & $0.94^{\mathrm{g}}$ \\
RL1 & $19.90 \pm$ & $90.00 \pm$ & $0.52 \pm$ & $0.79 \pm$ & $0.25 \pm$ & $1.44 \pm$ & $0.87 \pm$ & $0.11 \pm$ & $3.33 \pm$ \\
& $0.90^{\mathrm{f}}$ & $8.85^{\mathrm{bb}}$ & $0.15^{\mathrm{g}}$ & $0.12^{\mathrm{h}}$ & $0.01^{\mathrm{d}}$ & $0.52^{\mathrm{ee}}$ & $0.42^{\mathrm{g}}$ & $0.06^{\mathrm{dd}}$ & $0.94^{\mathrm{i}}$
\end{tabular}




\begin{tabular}{lccccccccc} 
RL2 & $23.93 \pm$ & $93.00 \pm$ & $0.71 \pm$ & $0.98 \pm$ & $0.39 \pm$ & $1.52 \pm$ & $1.79 \pm$ & $0.13 \pm$ & $4.48 \pm$ \\
& $0.90^{\mathrm{a}}$ & $8.85^{\mathrm{a}}$ & $0.15^{\mathrm{a}}$ & $0.12^{\mathrm{a}}$ & $0.01^{\mathrm{a}}$ & $0.52^{\mathrm{b}}$ & $0.42^{\mathrm{a}}$ & $0.06^{\mathrm{b}}$ & $0.94^{\mathrm{a}}$ \\
$\mathbf{R L 3}$ & $20.33 \pm$ & $87.33 \pm$ & $0.56 \pm$ & $0.74 \pm$ & $0.20 \pm$ & $1.46 \pm$ & $1.10 \pm$ & $0.10 \pm$ & $4.04 \pm$ \\
& $0.90^{\mathrm{e}}$ & $8.85^{\mathrm{c}}$ & $0.15^{\mathrm{gg}}$ & $0.12^{\mathrm{g}}$ & $0.01^{\mathrm{ff}}$ & $0.52^{\mathrm{d}}$ & $0.42^{\mathrm{c}}$ & $0.06^{\mathrm{e}}$ & $0.94^{\mathrm{d}}$ \\
$\mathbf{R} L 4$ & $19.47 \pm$ & $86.67 \pm$ & $0.54 \pm$ & $0.92 \pm$ & $0.30 \pm$ & $1.96 \pm$ & $1.19 \pm$ & $0.12 \pm$ & $3.87 \pm$ \\
& $0.90^{\mathrm{g}}$ & $8.85^{\mathrm{ddd}}$ & $0.15^{\mathrm{f}}$ & $0.12^{\mathrm{cc}}$ & $0.01^{\mathrm{b}}$ & $0.52^{\mathrm{a}}$ & $0.42^{\mathrm{b}}$ & $0.06^{\mathrm{cc}}$ & $0.94^{\mathrm{f}}$ \\
\hline
\end{tabular}

\section{Body composition (carcass) of Red tilapia}

The study was extended to apply the lipid- extracted algae cells in red tilapia feeding. The results in Figure (6) showing improvements of their protein contents in the $50 \%$ substitutions.

AnentThe chemical composition of the red tilapia body in Fig (5), the highest protein $(\mathrm{CP})$ and dry matter DM were achieved by A1, RL2 (55.10, 23.70 \& 54.90, $23.59) \%$ respectively compared with $\mathrm{CO}(50.42,22.60) \%$. Also the highest lipid (EE) and ash contents were obtained by $\mathrm{CO}, \mathrm{A} 1, \mathrm{~A} 2, \mathrm{~A} 3 \mathrm{~A} 4$ then RL2, among other treatments,all at significance $(\mathrm{P}<0.05)$.

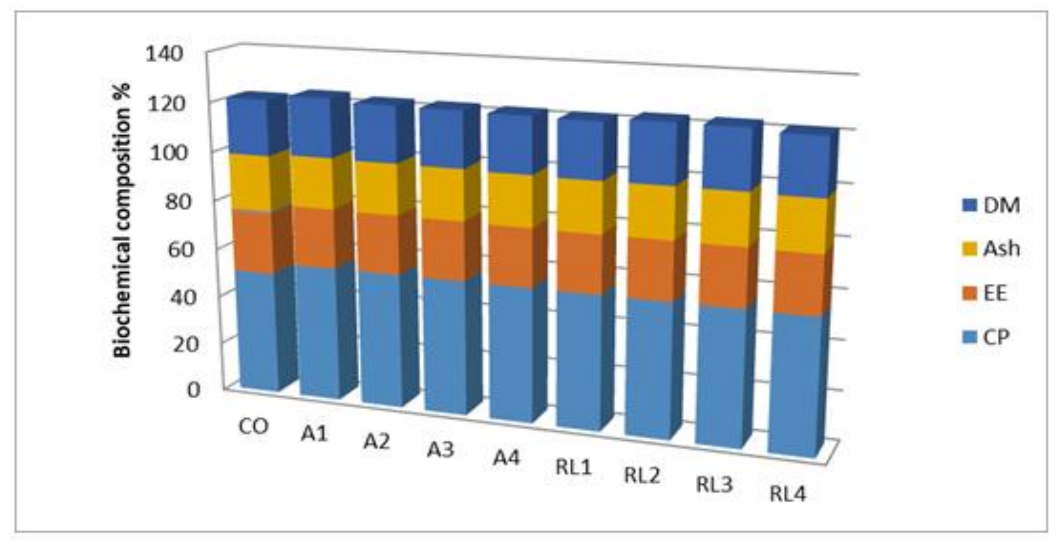

Fig. 6: The effect of diets on biochemical composition of carcass Red tilapia.

\section{DISCUSSION}

In this study, we are examine the different sources of organic carbon and nitrogen at 50\% inclusion with F/2 medium. The growth of $N$. oceanica and the characterization of their biomass contents were assessed for further applications in Red tilapia feeding with various incorporations as additives substituting Soybean in formulating diet.

Monitoring of the algae growth was determined during the exponential phase that mainly relied upon the inocula sizes, culture conditions and the constituents of the growth media (Jayasankar and Valsala, 2008; El-kassas et al., 2016). Growth evaluation, represented by biomass and algal biochemical analysis are two essential attributes to evaluate the prospective of a species as promising candidates for different applications (Araujo and Garcia, 2005; El-kassas et al., 2016) for Chorella spp. and their application in aquaculture feeding for N.oceanica (Ashour et al., 2019). In the present study, N.oceanica began their stationary phase of growth on the 10th day of incubation where achieved the maximum biomass value by fructose medium (A) followed by rumen liquor (RL) while the lowest biomass was obtained by lactose (B). Similar studies using the same carbon sources by Velu et al. (2015) revealed that the biomass yield and lipids contents were considerably increased with fructose in relation to controls. Supplementation with lower glucose $(0.5-1.0 \mathrm{~g} / \mathrm{L})$ significantly 
promoted the synthesis of chlorophylls and protein availability per unit culture, but decreased the lipid quantity per unit in dry weight bases of biomass under light conditions, whereas the addition of overdose glucose concentrations $(4,8$ or $16 \mathrm{~g} / \mathrm{L})$ resulted in a light yellow appearance (Chai et al. (2018). They also cleared that high concentrations of fructose led to a green-colored culture and that observation agree with our present study when low glucose concentrations of $0.5 \mathrm{~g} / \mathrm{L}$ in the light decreased the biomass and green pigment whereas the same fructose supplementation increased the green appearance and biomass content while lactose addition caused a subtle change in pigment contents. In this respect, glucose stimulated rapid growth of the algae because it is simple sugar and can be easily transformed to produce acetyl-CoA, which was then utilized in multiple pathways including the synthesis of fatty acids. Glucose and fructose had the same number of carbon numbers; they were decomposed by different enzymes. Glucose is turned into glucose-6-phosphate, which is key sporadic product involved in both glycolysis and pentose-phosphate cycle (Stewart, 1974). However, fructose could not be directly converted to glucose-6- phosphate in microalgae. Consequently, the growth rate was slightly decreased when fructose was used as the carbon source compared to glucose. Similarly, in our experiment the tested microalga N.oceanica showed high lipid accumulation in the order of glucose, fructose but fewer productions were seen in lactose(Chai et al., 2018; Velu et al., 2015). Otherwise, In the work of Morales-Sanchez et al. (2013), fructose promoted growth more than glucose because other species show the opposite response, especially considering Neochloris sp., which preferred glucose and consumption of fructose was null over a period of 5 days . That may be attributed to that each organism has its uniqe nutrients affinities which lead to species-specificity in growth kienetics. However, they recommended in the further research, utilizing alternative substrates instead of fructose to reduce the production cost for mass cultivation.

The results in using of carbon sources are close in some constituents such as protein and fat with (Velu et al., 2015) and the difference in some results including carbohydrates in the study using the same sources of carbon with different inclusion rates as in algae species (Nannochloropsis salina, Dunaliella tertiolecta, Tetraselmis suecica). Also, the results of the use of chicken manure (Ungsethaphand et al., 2009) were different for use in manure with sodium bicarbonate and urea for the development of spirulina alga. They were close with Xiao et al. (2013); Xiao-Nian et al. (2016), due to different media types.

The total lipid extracted from different media was found to have accumulated enormous saturated fatty acids RL, PM, C, B and A respectively. It was higher that obtained by Xiao et al. (2013). The major fraction of fatty acids belonging to N.oceanica was PUFAs.

The main components of SFAs in the studied N.oceanica were Myristic acid (C14:0), Palmitic acid (C16:0), Stearic acid (C18:0). Xiao et al. (2013); Xiao-Nian et al. (2016) declared that palmitic acid is the major constituent in the crude lipids of the N.oceanica. Accordingly, Bakhtiarvandi et al. (2014) stated that, SFAs are used as a substrate for energy. These results were also in conformity with finding of (Elkassas et al., 2016) for Chlorella sp. They reported that after oil extraction, there were no significant losses in the other considering algae metabolites, saturated fats were the main constituents in the fatty acids methyl esters FAMEs, meaning that Palmitic and stearic acids were dominant. Meanwhile, amino acid contents of the experimental marine Chlorella species were contained lysine, methionine and histidine; but were deficient in cysteine. Therefore, the USFAs are essential elements of nutrition. The results of many studies have shown the presence of UFA in algae fats. Patil et al. 
(2005) concluded the presence of UFAs in algae lipids; they have been considered as well springs and outputs of PUFAs for aquaculture industry.

Also, Oleic acid was recorded in N.oceanica, these results are consistent with those reported (Xiao et al., 2013). Moreover, (Gerasimenko et al., 2010) reported that algae fats can be a source of PUFAs of the $\omega-3$ and $\omega-6$ series. In this work, PUFAs$\omega 6$ was detected with approximately medium concentrations and the $\omega-3$ was low in N. oceanica studied.

The lipid extracted from algae, including the saturated fatty acids, is a good source for biodiesel. Whereas, the economy comprise was a great importance in the commercial viability of production of biofuel in Mexico (Sun et al., 2011). The cost of producing micronutrients depends on various factors such as biomass yield, oil content, and volume of production systems. The economic viability of biomolecular biofuel production is improved biomass content. The requirements of nautral carbon, nautral alternatives make micro algae one of the best sources of biofuels (Chisti, 2007).

Feeding marine creatures under culture conditions is one of the most important challenges to improve performance and ensure production processes. In this study of the use of N.oceanica biomass residues as protein source for feeding Red tilapia larvae, the results were similar to that of Eryalcin and Yildz (2015), who used $N$. oculata alga in Sea bream larvae feeding and found that the biochemical components of the larvae was higher as in our work due to the different species of fish and the use of algae in its complete cell components.

It was also close to El-Sheekh et al. (2014) when used spirulina in the diet improving biochemical composition of red tilapia. More recent studies, Elkassas et al. (2016); Ashour et al. (2019) investigated that the development and survival of Artemia franciscana showed significant increases when fed on lipid extracted algae residuals. Such strategy is in accordance with our results which are supposed to be an important achievement and confirm that the residual algae biomass can be significantly used for aquaculture feeding.

\section{CONCLUSION}

From the results in this study, authors suggested that, in respect to cost effectiveness and commercial avaliability, Romen liquor RL was preferred as a suitable carbon nitrogen source at 50:50\% with F/2 medium better than fructose for commercial cultivation of microalga N.oceanica in a large scale, biodiesel production and also recommended using its residual lipid-free biomass at concentration $50 \%$ as feed for improving red tilapia aquaculture.

\section{REFERENCES}

Abomohra, A.; El-Sheekh, M. ; Hanelt, D. (2014). Pilot cultivation of the chlorophyte microalga Scenedesmus obliquus as a promising feedstock for biofuel, Biomass Bioenergy, 64: 237-244.

Ajitha Mol, A.( 2016). Study the Production of Rotifer Culture in Different Concentration of Microalgae with Combination of Manure. Int. J. Pure App. Biosci. 4 (4): 321-326 (2016) ISSN: 2320 - 7051.

Arau'jo,S. and Garcia,V. (2005).Growth and biochemical composition of the diatom Chaetoceros cf.wighamii Brightwell under different Temperature,Salinity and 
carbon dioxide levels I.protein,carbohydrate and lipids.Aquaculture 246,405412.

Ashour, M.; M. Elshobary, E.; El-Shenody, R.; Kamil, A. Abomohra, A. (2019). Evaluation of a native oleaginous marine microalga Nannochloropsis oceanica for dual use in biodiesel production and aquaculture feed.Biomass and Bioenergy 120(2019)439-447.

AOAC, (Association of Analytical Chemists) (2000). Official Methods of Analysis, 15th edition, Washington, D.C; U.S.A.

Bakhtiarvandi, NK.; Kenari, AA.; Nazari, RM. ; Makhdoomi, C. (2014). Ontogenetic changes in lipids, fatty acid, and body composition during larval stages of Caspian kutum (Rutilus frisii kutum). IJFS 13 (2): 365-383.

Behera ,S.; Singh, R.; Arora, R. ; Sharma, N. K. ; Shukla, M.; Kumar, S. (2015). Scope of Algae as third generation Biofuel .Front Bioeng Biotechnol. 2014; 2: 90. Published online 2015Feb.11. doi: 10.3389/fbioe.2014.00090 PMCID: PMC4324237.

Bhatta, R.; Uyeno, Y.; Tajima, K.; Takenaka, A.; Yabumoto, Y.; Nonaka, I.; Enishi, O.;Kurihara, M.(2009). Difference in the nature of tannins on in vitro ruminal methane and volatile fatty acid production and on methanogenic archaea and protozoal populations. J Dairy Sci., 92(11): 5512-22. doi: 10.3168/jds.2008-1441.

Bondioli, P.; Bella, L. D.; Rivolta G.; Zittelli G. C.; Bassi N.; Rodolfi L.; Casini, D.; Prussi, M.; Chiaramonti, D. ; Tredici, M. R. (2012). Oil production by the marine microalgae Nannochloropsis sp. F. and M- M24 and Tetraselmis suecica F and M-M33. Bioresource Technology 114: 567- 572 .

Brody, S. (1945). Bioenergetics and Growth (Rheinhold, New York).

Chai, S.; Shi , J.; Huang, T. ;Guo ,Y., Wei, J., Guo ,M.; Li, L.; Dou, S.; Liu ,L.; Liu, G. (2018). Characterization of Chlorella sorokiniana growth properties in monosaccharide-supplemented batch culture. PLoS One. 2018; 13(7): e0199873. Published online 2018 Jul .3. doi: 10.1371/journal.pone.0199873 PMCID:PMC6029798.

Castell, J.D. and K. Tiews, (1980). Report on the EIFAC, IUNS and ICES working group on the standardization of methodology in fish nutrition research. Hamburg, Federal Republic of Germany, EIFAC Technical Paper.

Chen, C.; Zhao, X.; Yen, H.; Ho, S.; Cheng, C.; Lee, D.; Bai, F. ; Chang, J. (2013). Microalgae-based carbohydrates for biofuel production. Biochemical Engineering Journal 78: 1-10.

Chen, C.Y.; Huang, H.C.; Ho, S.H. ; Chang, J.S. (2015). Enhancing the production of eicosapentaenoic acid (EPA) from Nannochloropsis oceanica CY2 using innovative photobioreactors with optimal light source arrangements, Bioresour. Technol. 191:407-413.

Chisti, Y. (2007). "Biodiesel from microalgae," Biotechnology Advances. View at Publisher. View at Google Scholar. View at Scopus vol. 25: no. 3, pp. 294-306,

Choi ,H.J. and Yu, S.W.(2015). Influence of crude glycerol on the biomass and lipid content of microalgae. Biotechnol Biotechnol Equip. 2015;29:506-513. doi: 10.1080/13102818.2015.1013988.

Dubois, M.; Gilles, KA.; HamiHon, JK. ; Smith F. (1959). Phenol-sulphic method in carbohydrates chemistry. Wistler LR, Wolform RL (eds) Academic Press, New York, pp 388-403.

Egan, H.; Kirk, R.S. ; Sawyer, R. (1981). Pearson's Chemical Analysis of Foods. 8th Edition, Churchill Livingstone, London, New York.

El-Dahhar, A. A.; Abdel Rahim , M. M.; Shawky , W. ; Hafez , A. M.(2016). Effect of early weaning on survival and growth of European sea bass, Dicentrarchus Labrax larvae 
using an equal mixture of sea and well water. Journal of the arabian aquaculture society.Vol. 11 No 1. DOI: 10.12816/0042805.

El-Kassas,H.Y.; Mohammady,N.G.;El-Sayed,H.S.; ELSherbiny,B.A.(2016).Growth and Biochemical variability of complete and lipid extracted Chlorella species (application for Artemia faranciscana feeding).Rendiconti Lincei December 2016, Volume 27, Issue 4, pp 761-774.

El-Sheekh, M.; El-Shourbagy, I.; Shalaby, S. ; Hosny, S. (2014). Effect of feeding Arthrospira platensis (Spirulina) on growth and carcass composition of Hybrid Red Tilapia (Oreochromis niloticus $x$ Oreochromis mossambicus). Turkish Journal of Fisheries and Aquatic Sciences 14:471-478 .

Eryalcin ,K. M. and Yildz,M. (2015). Effects of Long- Term Feeding with dried microalgae added microdiets on growth and fatty acid composition of gilthead Sea Bream (Sparus uratua L., 1758), Turkish Journal of Fisheries and Aquatic Sciences 15:899-909.

Feng, D.; Chen,Z.; Xue,S. ; Zhang, W. (2011). Increased lipid production of the marine oleaginous microalgae Isochrysis zhangjiangensis (Chrysophyta) by nitrogen supplement. Bioresour. Technol. (doi: 10. 1016/j. biortech. 04.006).

Fisher, S.; Willis,D. ; Pope,K.(1996). An assessment of burbot (Lota lota) weightlength data from North American populations. Canadian Journal of Zoology 74:570-575.

Gallardo, P.P.: Alfonso, E.: Gaxiola, G.; Soto, L. A. ;Rosas, C. (1995). Feeding schedule for panaeus setiferus larvae based on diatoms Chaetoceros ceratosporum.Flagellates, Tetraselmis chuii and artemia nauplii. Aquaculture 131: 239- 252.

Geldenhuys, D. J.; Walmsky, D. J. ; Tofrien. D. J. (1988). Quality of algal material produced on a fertilizer - tap water medium in outdoor plastic enclosed systems. Aquaculture .68:157-164.

Gerasimenko, N.I.; Busarova, N.G. ; Moiseenko, O.P. (2010). Seasonal changes in the content of lipids, fatty acids, and pigments in brown alga Costaria costata. Russ J Plant Physl 57 (2): 205-211.

Guillard, R.R.L. and Ryther, J.H. (1962). Studies on Marine Planktonic Diatoms I. Cyclotella nana Hustedt and Detonula confervacea (Cleve) Gran. Canadian Journalof Microbiology, 8, 229-239. https://doi.org/10.1139/m62-029.

Habib, M. A. B.; Yusoff, F. M.; Phang. S. M.; Ang, K. J. ; Mohamed, S. (2003). Culture and nutritional value of Moina micrura Pallas fed on Chlorella vulgaris grown in digested palm oil mill effluent. Asian Fish. Sci., 16 (3): 253- 261.

Han, J. ;Zhang, L. ; Wang ,S.; Yang ,G.; Zhao, L. ; Pan ,K. (2016). Co-culturing bacteria and microalgae in organic carbon containing medium. Journal of Biological Research- Thessaloniki 2016 .23:8https://doi.org/10.1186/s40709016-0047-6.

Hasan, M. and Chakrabarti, R. (2009) .Use of Algae and Aquatic Macrophytes as Feed in Small scale Aquaculture: a Review, Food and Agriculture Organization of the United Nations, FAO, Rome, p. 125 Report No.531.

Hasanein,S.S.;Saleh,N.E.;El-Sayed, H.S; Helal A.M. (2018). The Effect of dietary supplementation of Spirulina platensis and Chlorella vulgaris algae on thegrowth and disease resistance of the sea bass (Dicentrarchus labrax). Egyptian Journal of Aquatic Biology \& Fisheries Vol. 22(4): 249- 262 (2018) .ejabf.journals.ekb.eg.

Heflin, L.; Gibbs, V.; Powell, M.; Makowsky, R.; Lawrence, J.; Lawrence, A. ; Watts, S. (2012). Effect of dietary protein and carbohydrate levels on weight gain and 
gonad production in the sea urchin Lytechinus variegatus, Aquaculture 358359.

$\mathrm{Hu}, \mathrm{H}$. and Gao,K. (2003). Optimization of growth and fatty acid composition of a unicellular marine picoplankton, Nannochloropsis sp., with enriched carbon sources. Biotechnology Letters 25: 421-425.

Jain ,S. and Singh, S. G.(2013). Low cost medium formulation using cow dung ash for the cultivation of Cyanobacterium: Spirulina (Arthrospira) platensis. Emir. J. Food Agric. 2013; 25(9): 682-691doi: 10.9755/ejfa.v25i9.16394

Jayanegara, A.; Togtokhbayar, N.; Makkar, H.P.S.; Becker, K. (2009) . Tannins determined by various methods as predictors of methane production reduction potential of plants by an in vitro rumen fermentation system. Anim Feed Sci Technol. 2009;150:230-237.

Jayasankar,R.and Valsala,K.K.(2008). Influence of different concentrations of sodium bicarbonate on growth rate and chlorophyll content of Chlorella salina J. Mar. Biol. Ass. India, 50 (1) : 74 - 78, January - June 2008.

Junying, Z.; Junfeng, R. ;Baoning Z. (2013). Factors in mass cultivation of microalgae for biodiesel. Chinese Journal of Catalysis 34, 80- 100.

Lavens, P. and Sorgeloos, P. (1996). Manual on the production and Use Live Food for Aquaculture, FAO, Laboratory of Aquaculture and Artemia Reference Center, University of Ghent, Ghent, Belgium.

Lin, T.S. and Wu, J.Y.(2015). Effect of carbon sources on growth and lipid accumulation of newly isolated microalgae cultured under mixotrophic condition. Bioresour Technol. 2015;184:100-107. doi: 10.1016/j.biortech.2014.11.005.

Makkar, H.P.S. (2003).A Laboratory Manual. Kluwer Academic Publishers; Dordrecht, the Netherlands: 2003. Quantification of Tannins in Tree and Shrub Foliage

Manuel J.; Pacheco V.; Cadena,M.; Sanchez -Saavedra M. D. P.; Tovar Ramirezy „D.; Rangel-Davalos,C. (2010). Effect of culture medium and nutrient concentration on fatty acid content of Chaetoceros muelleri. Rev Lattiinoam Biiottecnoll Amb Allgall 1(1): 6- 15 .

Markou, G.; Vandamme, D. ; Muylaert K. (2014). Microalgal and cyanobacterial cultivation: the supply of nutrients. Water Research 65, 186-202. DOI: 10.1016/j.watres. 07.025.

Martinez-Cordova, L. R.; Campana - Torres,A.; Martinez- Porchas , M.; Lopez Elias, J. A. ; Garcia - Sifuentes ,C. O. (2012). Effect of alternative medium on production and proximate composition of the microalgae Chaetoceros muelleri as food in culture of the copepod Acartia sp. Lat. Am. J. Aqual. Res., 40 (1): $169-176$.

Mondal,M.; Ghosh, A.; Goswami,S; Oinam, G.; Tiwari, O. N.; Das, P.; Gayen, K.; Mandal, M. K.; Halder, G. N.(2017). Production of biodiesel from microalgae through biological carbon capture: a review.3 Biotech. 2017 Jun; 7(2): 99. Published online 30. doi: 10.1007/s13205-017-0727-4PMCID: PMC5449280.

Morales-Sanchez, D.; Tinoco-Valencia, R.; Kyndt, J. ; Martinez, A.(2013). Heterotrophic growth of Neochloris oleoabundans using glucose as a carbon source. Biotechnol. Biofuels 6, 100, https://doi.org/10.1186/1754-6834-6-100 (2013).

Mutlu, Y. B.;lik, O.; Uslu, L.; Koc ,K. ;Durmaz,Y. (2011). The effects of nitrogen and phosphorus deficiencies and nitrite addition on the lipid content of Chlorella vulgaris (Chlorophyceae). African Journal of Biotechnology Vol. 10 (3). pp, 453- 456 . 
Naumann, H. D; Tedeschi, L. O.; Zeller W. E.; Huntley N. F. (2017). The role of condensed tannins in ruminant animal production: advances limitations and future directions R. Bras. Zootec., 46(12):929-949, 2017. Brazilian Journal of Animal Science. ISSN 1806-9290 Zootecnia

Newman, R.M. and Martin, F.B. (1983). Estimation of fish production rates and associated variances. Canadian Journal of Fisheries and Aquatic Sciences, 40: 1729 - 1936.

Patil, V.; Källqvist, T.; Olsen, E.; Vogt, G. ; Gislerqd H.R. (2007). Fatty acid composition of 12 microalgae for possible use in aquaculture feed. Aquaculture Int 15: 1-9.

Patil, V.; Reitan, KI.; Knudsen,G. ; Mortensen, L. ; Källqvist ,T. ; Olsen ,E. (2005). Microalgae as source of polyunsaturated fatty acids for aquaculture. Plant Biol 6:57-65

Radwan, S.S. (1978). Coupling of two dimensional thin layer chromatography for quantitive analysis of lipid classes and their constituent fatty acids. J.Chromatogr. Sci., 16: 538 - 542.

Ricker, W.E. (1975): Computation and interpretation of biological statistics of fish populations. Fish . Res. Board Can. Bull., 191: 1- 382.

Rois, D. S.; Carmen, M.; Torres, C.; Torras, J.; Salvado, Josep M.; Mateo-Sanz ; Laureamo Jimenez. (2013). Microalgae - based biodiesel: Economic analysis of downstream process realistic scenarios. Bioresource Technology. 136: 617 625 .

Sachez - Saavedra, M. P. and Voltolina, D. (2005). The growth rate, biomass production and composition of Chaetoeros $s p$. Growth with different light sources . Aquacult. Eng 35 (2):161-165.

Sales, R. and Abreu, P. C.(2014). Use of natural pH variation to increase the flocculation of the marine microalgae Nannochloropsis oculata. Appl. Biochem Biotechnol (2015)175:2012-2019 DOI 10.1007/s12010-014-1412-2.

SAS. (2004). SAS/STAT User guide, Version 9.1.2. Cary .NC, USA: SAS Institute Inc.

Sauer, M., Marx, H. Mattanovich, D. (2012). From rumen to industry. Microbial Cell Factories 11(1):121 DOI: 10.1186/1475-2859-11-121.

Sharma,A. K.; Sahoo, P. K. ; Singhal, S.; Patel A.(2016). Impact of various media and organic carbon sources on biofuel production potential from Chlorella spp.3 Biotech. 2016 Dec; 6(2): 116. Published online 2016 May 31. doi: 10.1007/ s13205-016-0434-6.PMCID:PMC4909020

Shelf, G.; Oron, G. ; Moraine. R. (1978). Economic aspects of microalgae production on sewage. Archiv für Hydrobiologie beiheft Ergednisse der Limnologie, 11: 280- 294.

Singh, M.; Reynolds, D.L. ; Das, K.C. (2011). Microalgal system for treatment of effluent from poultry litter anaerobic digestion. Bioresour. Technol. 102: 10841-10848.

Sun, A.; Davis, R.; Starbuck, M.; Ben-Amotz, A.; Pate, R. ;Pienkos, P. T. (2011). "Comparative cost analysis of algal oil production for biofuels," Energy, vol. 36, no. 8, pp. 5169-5179, View at Publisher. View at Google Scholar. View at Scopus 
Ungsethaphand , T. ; Peerapornpisal, Y. ; Whangchai, N. (2009). Production of Spirulina platensis using dry chicken manure supplemented with urea and sodium bicarbonate. Maejo Int. J. Sci. Technol. 3: (03), 379-38.

Vega, J.; Pacheco, M.; Marco, A.;Cadena R.; Del, P.; Sanchez, S. M. ; Dariel, T.; Ramirezy, C.; Rangel D. (2010). Effect of culture medium and nutrient concentration on fatty acid content of Chaetoceros muelleri. Rev Lattiinoam Biiottecnoll Amb Allgall 1(1): 6- 15 .

Velu,P. ; Peter,M. J. ; Sanniyasi,E. (2015). Effect of Various Carbon Sources on Biochemical Production in Marine Microalgae Nannochloropsis salina (Eustigmatophyceae), Dunaliella tertiolecta (Chlorophyceae) and Tetraselmis suecica (Chlorodendrophyceae), Int.J.Curr.Microbiol.App.Sci 4(3): 207-215.

Vymazal, J. (1995). Algae and Element Cycling in Wetlands. CRC press, Inc. Boca Raton. USA. Pp.689.

Wan, C.; Bai, F.W. ; Zhao, X. (2013). Effects of nitrogen concentration and media replacement on cell growth and lipid production of oleaginous marine microalga Nannochloropsis oceanica DUT01, Biochem. Eng. J. 78: 32-38.

Xiao, Y.; Zhang, J.; Cui, J.; Feng, Y. ; Cui, Q. (2013). Metabolic profiles of Nannochloropsis oceanica IMET1 under nitrogen-deficiency stress. Bioresour Technol. 2013 Feb;130:731-8. doi: 10.1016/j.biortech.2012.11.116.

Xiao-Nian, M. ; Tian-Peng, C.; Bo, T.; Lui ,J ; Feng, C. (2016). Lipid production from Nannochloropsis Mar.Druge 14,61: doi:10.3390/md 14040061.

Yamaguchi, K. (1997). Recent advances in microalgae bioscince in Japan, with apecial reference to utilization of biomass and metabolites : a review. J. Appl. Phycol., 8: 487- 502 .Zoology Department, Faculty of Science,Ain Shams University, Cairo, Egypt ISSN 1110 - 6131.

Zuo, R.; Hou, S.; Wu, F.; Song, J.; Zhang, W.; Zhao, C. ; Chang, Y. (2017). Higher dietary protein increases growth performance, anti-oxidative enzymes activity and transcription of heat shock protein 70 in the juvenile sea urchin (Strongylocentrotus intermedius) under a heat stress, Aquacult. Fish. 2: 18-23. 